\title{
Factors Affecting Quality of Home Based Long-term Care Provision for the Bedridden Patients in Chandigarh, North India
}

\author{
${ }^{1}$ Tarundeep Singh, ${ }^{2}$ Amarjeet Singh Minhas
}

\begin{abstract}
Objective: To determine the factors affecting the quality of home based long-term care (LTC) provision for the adult bedridden patients in Chandigarh, India.
\end{abstract}

Materials and methods: This cross-sectional study was conducted on 100 bedridden patients in Chandigarh. Disability was assessed using the Katz index and an interview schedule based on Craig handicap assessment and reporting technique (CHART) was used to assess the care provision to the bedridden patients. Available medical records and brief medical examination were also conducted on the spot. Quality of care was assessed based on the Donabedian model. Factors associated with the quality of care provision, based on literature, were examined for association in the study cases.

Results: Mean age of the bedridden patients was 69 years. Sixtyeight patients lived in joint families. All had total dependence in the domains of bathing, dressing, toileting and transfer. The commonest cause of disability was neurological diseases. Mean duration of being bedridden was 16.4 months. Though the rates of complications like urinary infections (89\%), bedsores $(54 \%)$ were quite high, $57 \%$ patients reported satisfaction with the quality of care they were receiving. However, only 18 males and 6 females subjects were receiving good quality care according to our evaluation. Ownership of property/money by the subject was the only factor found to be associated with good quality of care. Gender of the subject, degree of disability, type of family in which the subject was living in and whether the patient is currently married or not did not seem to significantly affect the quality of care received by the subjects.

Conclusion: Though more than half of the study subjects reported subjective satisfaction with the quality of care being received, objective evaluation based on the study criteria showed that only a quarter were actually receiving good quality care. Furthermore, the economic worth seemed to positively influence the quality of care being received by the subjects.

Keywords: Bedridden, Disability, Quality of care.

\footnotetext{
${ }^{1}$ Assistant Professor, ${ }^{2}$ Professor

${ }^{1}$ Department of Community Medicine, Government Medical College and Hospital, Chandigarh, India

${ }^{2}$ Department of School of Public Health, Postgraduate Institute of Medical Education and Research, Chandigarh, India

Corresponding Author: Tarundeep Singh, Assistant Professor, Department of Community Medicine, Government Medical College and Hospital, Chandigarh, India, Phone: 01722601023, e-mail: tarundeep.singh@gmail.com
}

How to cite this article: Singh T, Minhas AS. Factors Affecting Quality of Home Based Long-term Care Provision for the Bedridden Patients in Chandigarh, North India. J Postgrad Med Edu Res 2015;49(3):126-131.

\section{Source of support: Nil}

\section{Conflict of interest: None}

\section{INTRODUCTION}

Demographic transition has resulted in increasing life expectancy and an increasing proportion of elderly persons in populations all over the world. ${ }^{1}$ A parallel epidemiologic transition has led to a predominance of chronic diseases. Hence, an increasing number of aged persons are living increasing proportions of their lives with chronic diseases. ${ }^{2}$ Many of such people need longterm personal assistance in their activities of life due to severely disabling and chronic nature of their diseases. ${ }^{2}$

Though governments all over the world have launched several healthcare programs for their care, most of the persons with chronic and severely disabling diseases are cared for at home, with family members and friends providing the bulk of care. ${ }^{3}$ This situation has led to reorientation of healthcare systems in the developed countries from hospitals and institutions to the domiciliary care arrangements which the chronically disabled also prefer and use. ${ }^{3-8}$ Shifting of long-term care provision in developed countries from hi-tech medical institutions to domiciliary settings has brought into focus the quality of care provided to the patients at home. While data about the quality of care provided in hospitals, nursing homes, residential institutions is available directly or indirectly, data about the quality of long-term care (LTC) provided to the severely disabled at their own homes is difficult to gather because of the multiple sociodemographic and interpersonal factors involved. ${ }^{9}$

In India, the situation is very different. Hi-tech care for the bedridden is practically non-existent. Hospital based or institution based care for the bedridden patient is also not available on a long-term basis. Family members and friends provide most of the LTC for the bedridden patients. However, data on quality of home-based LTC is scarce. Against this background the present study 
was conducted to assess the quality and determinants of home-based LTC provision for the bedridden patients in Chandigarh city, India.

\section{MATERIALS AND METHODS}

This cross-sectional study was conducted between in the planned sectors of Chandigarh city. As per the 2001 census, $5.1 \%$ of the city's population is above 65 years of age. ${ }^{10}$ The investigator accessed the addresses of patients who were treated for chronic debilitating diseases during 1 year preceding the study from the record files of government and private hospitals in Chandigarh. Patients residing in Chandigarh were contacted and their current health status was enquired. Senior Citizens Association, trauma centers and prosthesis providing centers, pharmacists, physiotherapists, traditional healers and masseurs were also contacted and asked to provide addresses of such patients on their records. This process was carried out along with concurrent interviews and data collection from patients, and further recruitment was stopped when a total of 100 patients had been interviewed. Maximum number of patients (35) was contacted through the private practitioners.

An interview schedule based on Craig handicap assessment and reporting technique $(\mathrm{CHART})^{11}$ was used to assess the care provision to the bedridden patients. $\mathrm{Katz}^{12}$ index of activities of daily living was used to assess the degree of disability. All available medical records of the patients were reviewed and a brief on the spot examination was conducted to evaluate the current health status of the patient. Scoring for quality of care was done by taking into account four structural, five process and six outcome indicators chosen for their representativeness of the care giving process as suggested by Donabedian. ${ }^{13}$ Presence of a positive indicator was given a score of one whereas its absence or presence of a negative indicator was marked as zero (Table 1). Out of the total maximum possible score of 15 , patients having scores of 11 and above were arbitrarily considered as receiving good quality care, patients scoring 7 to 10 and below seven were considered as receiving average and poor quality care respectively. Epi info version 2000 was used for analysis. Percentage, mean, standard deviation and Chi-square test were used for the interpretation of data.

\section{Operational Definitions}

Bedridden case: All cases above 12 years of age who had been confined to bed for 15 days or more, for $90 \%$ of the time during the day and who were unable to get out of bed without assistance. ${ }^{13}$

Key caregiver: The person in the family who was primarily responsible for the care of the index case.
Table 1: Indicators for quality of care score

\begin{tabular}{|c|c|c|c|}
\hline \multirow[b]{2}{*}{ Indicators } & & \multicolumn{2}{|c|}{ Responses } \\
\hline & & Yes & No \\
\hline & Structures & & \\
\hline & $\begin{array}{l}\text { Last contact with the doctor within } \\
\text { last } 3 \text { months }\end{array}$ & & \\
\hline 2. & $\begin{array}{l}\text { Modifications done in the building/ } \\
\text { rooms of home }\end{array}$ & & \\
\hline 3. & Consulted an unqualified practitioner & & \\
\hline 4. & $\begin{array}{l}\text { X-rays done to assess the bone mass } \\
\text { after being bed ridden }\end{array}$ & & \\
\hline & Processes & & \\
\hline & $\begin{array}{l}\text { Waiting period (of }>30 \text { minutes) }>5 \\
\text { times/week }\end{array}$ & & \\
\hline & $\begin{array}{l}\text { Frequency of changing bedsheets } \\
(1 / 3 \text { days or more) }\end{array}$ & & \\
\hline 7. & Given medicines on time? & & \\
\hline & $\begin{array}{l}\text { Physician's advice for the subject } \\
\text { followed? }\end{array}$ & & \\
\hline & Visit by friends (>1/week) & & \\
\hline & Outcomes & & \\
\hline 10. & Bed sores & & \\
\hline 11. & Urine infections & & \\
\hline 12. & Chest infections & & \\
\hline 13. & Incontinence & & \\
\hline 14. & Constipation & & \\
\hline 15. & Satisfaction with care & & \\
\hline
\end{tabular}

${ }^{*}$ A positive response to question no. 1, 2, 4, 6 to 9 and 15 was given a score of 1 each and a negative response was given a score of 0 . Positive response to question no. $3,5,10$ to 14 was given a score of 0 each and a negative response was given a score of 1 . Total was summed to give a maximum possible score of 15

Exclusion criteria: All ambulatory cases were excluded, i.e. those who could get off the bed without assistance or those who could walk without assistance.

Ethical considerations: The subjects were informed about the purpose of the study. Only those willing to participate were included. Proxy consent was taken from the key care provider or the head of the family in cases who were not able to communicate.

\section{RESULTS}

Mean age of study patients was 67 years with maximum being in the age group of 16 to 60 and 71 to 80 years (29\%/ each) while 26 were in 81 years and older. Seventy-one patients were educated till above the graduate level. Fifty-one patients were currently married, 43 widowed/ widowers and 5 patients had never been married. Sixtyeight of the cases were living in joint families, 32 were in nuclear families and no patient was living alone (Table 2).

Neurological, musculoskeletal causes and old age were the predominant morbid conditions. Neurological disorders were concentrated $(15 / 38)$ in the 71 to 80 years age group. Parkinson's, CVA and Alzheimer's were the predominant morbid condition in those above 60 years 
Table 2: Profile of the patients $(n=100)$

\begin{tabular}{|c|c|}
\hline Variable & $N$ \\
\hline Age $>60$ years & 69 (mean age 67 years) \\
\hline \multicolumn{2}{|l|}{ Sex } \\
\hline Male: Female & 68: 32 \\
\hline Widowers & 17 \\
\hline Widows & 26 \\
\hline Joint family & 68 \\
\hline Family size $>5$ & 26 (average family size 4.8 ) \\
\hline $\begin{array}{l}\text { Per capita monthly income } \\
(>10,000)\end{array}$ & 47 (average ₹ 9620) \\
\hline $\begin{array}{l}\text { Education (graduate and } \\
\text { above) }\end{array}$ & 71 \\
\hline \multicolumn{2}{|l|}{$\begin{array}{l}\text { Common causes of } \\
\text { morbidity }\end{array}$} \\
\hline - Neurological & 38 (17 cerebral stroke cases) \\
\hline - Musculoskeletal & 28 (8 hip fractures, 7 osteoarthritis) \\
\hline - Old age & 17 \\
\hline $\begin{array}{l}\text { Duration since bed ridden } \\
\text { ( }>1 \text { year) }\end{array}$ & 43 (average time 16.4 months) \\
\hline Own property & 69 \\
\hline Currently working & 8 \\
\hline Current smoker & 2 (past use 27 ) \\
\hline Current alcohol use & None (past use 26) \\
\hline Current use of sedatives & 73 \\
\hline \multicolumn{2}{|l|}{ Dependent in $A D L$} \\
\hline Bathing & 100 (assisted 87, dependent 13) \\
\hline Dressing & 100 (assisted 90, dependent 10) \\
\hline Toileting & 100 (assisted 24, dependent 76) \\
\hline Transfer & 100 \\
\hline Continence & 42 \\
\hline Feeding & 22 \\
\hline
\end{tabular}

while Guillain-Barré syndrome and multiple sclerosis predominated in those below 60 years. Rheumatoid arthritis and fracture of spine were common in those under age 60 years, while fracture hip and osteoarthritis predominated in those above 60 years age. There were 3 cases of severe disability due to paralysis after spinal tuberculosis (cured) (aged 37, 45 and 64 years).

Mean duration of being bedridden was 16.4 months. Only five patients had been bedridden for more than 8 years with two being bedridden since birth due to microcephaly and hydrocephaly.

Diabetes (19) and hypertension (31) were the most common comorbid conditions in this group of bedridden cases.

Sixty-seven of the patients required between 4 and 5 hours of care daily, with 22 requiring 6 hours and more and 11 requiring 3 hours or less of care daily.

Thirty-five of the bedridden had consulted persons other than formally trained medical practitioners while 61 had tried some indigenous or traditional medicine during their illness. A common indigenous method used was to inhale the smoke of green leaves of a climber (9), Another was to take injections from 'gifted' people (11) especially by people afflicted with paralysis and stroke patients of musculoskeletal problems often used medicines prepared by local practitioners of indigenous systems of medicine (Hakeems and Vaids). Seventy percent of those bedridden due to old age were consulting private practitioners.

Fifty-eight of the patients had contact with their current treatment providing agency within the last 1 week to 3 months. Forty-six patients were being visited by doctors at their homes and fifty-seven patients were in touch with their doctors over the phone. The usual pattern was to consult the hospital or specialist for the disease related problems (e.g. Parkinson's, Guillain-Barré syndrome, etc.) and to consult private practitioners for the day to day problems, like bedsores, chest infection, urine infection, etc. which were not related to cause of disability but were the complications of being bedridden.

Eighty-seven patients needed some assistance in bathing one or more parts of the body while 13 were totally dependent. Twenty-one patients had no control over bowel and bladder. Of these, five were disabled due to musculoskeletal reasons, 10 due to neurological reasons and two due to old age. Twenty-one patients experienced occasional incontinence. Twenty-four patients were mobile with human and mechanical assistance. These 24 could also go to toilet. Remaining patients 76 were completely bed bound. Ninety patients needed some assistance in dressing and 10 were fully dependent. Only three patients had severe limitation in feeding. One patient had Ryle's tube in situ for feeding.

Medicines were given on time and the physician's advice was being followed for 95 of the patients.

The average expenditure on treatment for illness since being bedridden was 1.6 lakhs, with 23 patients having spent more than 3 lakh ₹. Of these 12 were bedridden due to neurological and eight due to musculoskeletal morbidities. The average monthly expenditure on treatments was ₹ 3,100.

Constipation was the most frequent (89) complication experienced by the bedridden patients. Urinary infection was the next most frequent complication (83). Eleven patients had urine infection three to five times, 27 patients had it more than five times while 53 had urine infection for one to three times since being bedridden. Overall, 54 patients had experienced at least one episode of bedsore. Chest infection (44) and urinary incontinence (39) were also frequent. Six patients had at least one episode of deep venous thrombosis (Table 3 ).

Forty-two patients said that they had bad smell around them. In 78 cases, bedsheets were changed once in 3 days. In 13 cases, it was once a week. Six patients reported that the sheets were changed as frequently as they wet their bed, which was sometimes more than once per day. In three cases bedsheets were changed daily. 
Table 3: Complications suffered by bedridden patients during the course of their illness

\begin{tabular}{|c|c|c|c|c|c|c|}
\hline Complications (ever present) & Bedsores & $\begin{array}{l}\text { Urinary } \\
\text { incontinence }\end{array}$ & $\begin{array}{l}\text { Deep venous } \\
\text { thrombosis }\end{array}$ & Chest infection & Constipation & Urinary infection \\
\hline \multicolumn{7}{|l|}{ Morbidity } \\
\hline Neurological $(n=38)$ & 20 & 16 & 4 & 20 & 34 & 35 \\
\hline Musculoskeletal $(n=28)$ & 17 & 9 & 1 & 13 & 24 & 24 \\
\hline Old age $(n=17)$ & 8 & 5 & 0 & 6 & 16 & 11 \\
\hline Cancer $(n=8)$ & 3 & 4 & 0 & 2 & 7 & 6 \\
\hline Others $(n=9)$ & 6 & 5 & 1 & 3 & 8 & 7 \\
\hline Total episodes of complications & 54 & 39 & 6 & 44 & 89 & 83 \\
\hline
\end{tabular}

Only 13 patients had ever had a radiogram done to assess their bone mass since they had become bedridden. Three of these patients were bedridden due to old age, seven were cancer patients, who also had bone scans done detect metastases.

Thirty-one patients said that friends visited them less than once a week, 43 were visited by friends one to three times per week. Friends visited eight patients daily. No friends visited 11 patients and with the remaining the frequency was variable.

Sixty-five of the patients responded that they had some property, liquid assets in the form of fixed deposits, government pension, or solid assets like the house, etc. in their names.

The mean expenditure on home environment modification was ₹ 30,250 . The most frequent modification done in the house for the patients was clearing of rooms of all extra furniture so that there was enough space for caregivers to move about and also to place wheelchairs or chairs with commodes (89). Next two most frequent changes were use of chairs with toilets and bedpans. Use of bed tables was also quite frequent (37).

Most frequent modifications in the bed were purchasing a mechanized bed (₹ 2,500) in which both the head and foot ends could be raised as per desire (23). Also frequently done was raising the height of the bed so as to avoid caregiver back strain while bending to support the patient. One patient had special bed with holes in the top so that he could be bathed while lying in the bed only.

Fifty-four of the patients said they were satisfied with the care that they are receiving, while 29 of the patients did not respond to the question.

Based on the Donabedian model assessment, 18 males and six females received good quality of care. Out of gender, current marital status, type of family the patient lives in, degree of disability of the patient and whether the patient had any property/money to her name, only the last factor, i.e. whether the patient had any property / money to his/her name significantly affected the quality of care received persons having property/money receiving better care (Table 4 ).

\section{DISCUSSION}

There is more to LTC than simple, safe and harm free care. Good LTC should make a positive contribution to the wellbeing of those it serves and at the very least; it should not reduce their quality of life. ${ }^{1}$

Since, the seminal work of Donabedian, ${ }^{13}$ measures of healthcare quality have been divided into three components: structures, process and outcomes. Structures refer to the components of healthcare system. Processes refer to the use of appropriate diagnostic, therapeutic and preventive modalities for individual patients. Outcomes refer to the consequences of treatment and can represent markers of disease progression (mortality, readmission), health status (symptoms, functioning, complications and quality of life) and/or costs. These components, when initially thought of, referred to the quality of acute care provided in hospitals and institutions, but were later used to measure the quality of LTC as well because the essential factors affecting quality of LTC could also be grouped under these broad components.

However, decline in functional status, as measured by an individual's loss of activities of daily living over a period of time, is now considered the most meaningful

Table 4: Factors affecting quality of care received by the patients

\begin{tabular}{|c|c|c|c|}
\hline Predictor & Good care & $\begin{array}{l}\text { Average/ } \\
\text { poor care }\end{array}$ & $\begin{array}{l}\text { Chi-square, } \\
\text { p-value }\end{array}$ \\
\hline \multicolumn{4}{|l|}{ Gender } \\
\hline (Male, Female) & $17: 7$ & $45: 31$ & $\begin{array}{l}1.046 \\
p=0.3205\end{array}$ \\
\hline Marital status & & & \\
\hline $\begin{array}{l}\text { (currently married: } \\
\text { divorced/separated/ } \\
\text { widowed }\end{array}$ & $14: 10$ & $37: 39$ & $\begin{array}{l}0.6796 \\
p=0.4097\end{array}$ \\
\hline \multicolumn{4}{|l|}{ Type of family } \\
\hline Joint: Nuclear & $17: 7$ & $51: 25$ & $\begin{array}{l}0.1165 \\
p=0.7329\end{array}$ \\
\hline \multicolumn{4}{|l|}{ Degree of disability } \\
\hline $\begin{array}{l}\text { Class E: Class F: } \\
\text { Class G: }\end{array}$ & $11: 11: 4$ & $37: 29: 10$ & $\begin{array}{l}0.6533 \\
p=0.7213\end{array}$ \\
\hline \multicolumn{4}{|c|}{$\begin{array}{l}\text { Ownership of property/ } \\
\text { money by patient }\end{array}$} \\
\hline Yes: No & $20: 4$ & $49: 27$ & $\begin{array}{l}3.033 \\
p=0.0408\end{array}$ \\
\hline
\end{tabular}


outcome assessment for quality of LTC provision as it is strongly linked to the quality of care given, encompassing all three components of the Donabedian model for quality of care assessment. ${ }^{13}$

In this study, the authors have used Donabedian's component based approach for assessment of quality of care as this was a onetime contact with subjects and repeated measurements of functional status were not possible. Also, since according to the inclusion criteria, the subjects were all bedridden and severely limited in activities of daily living at the beginning of the study, measurement of functional decline would not have been much different at the beginning and end of the study, even if this study was a prospective follow-up study unless the assessments were conducted over wide time intervals.

Though the subjects in this study were purposively chosen, it is unlikely that it is by chance that almost $70 \%$ of the subjects were over the age of 60 years. Data from many other studies shows that disability tends to accrue over the years in an individual's life and those over the age of 60 are more likely to be disabled than the younger aged persons. In this study, 29\% patients were in the age group of 15 to 59 years. One patient, now above 60 years of age, became disabled when he was below 60 years.

The issue of how care will be provided for the disabled and aged is a matter of debate all over the world. In the liberal welfare states, the primary responsibility of care for the disabled persons lies with the individuals and their families and the government acts only as a financier for those unable to provide for themselves. In the corporate-statist welfare regimes of countries, like UK, Switzerland, Germany, Austria, and Norway, the state takes responsibility for providing for acute as well as long-term care. ${ }^{14}$ In India, the state does not intervene in the lives of its citizens in a large way. The role of the Indian welfare state is limited to providing facilities, which a community cannot provide on its own.

Joint family system is still one of the common family forms and the family, friends, neighbors and volunteers share most of the actual burden of caregiving. Our study revealed that 68 patients were living within a joint family system and that $82 \%$ of the caregivers were family members of the bedridden patients.

Average monthly expenditure on LTC included the payments made to the hired helps and medicines used for the patient. In 74 of the patients, this was within 4,000 rupees (89 \$), which was quite affordable on a monthly basis. The expenditure pattern was similar in all the other morbidity groups, i.e. major part of expenditure was on manpower. Hence, in patients needing LTC, it appears that the monthly expenditure depends more on the intensity of needs of the patient and the ability of the family to provide care, and not on the nature of disease. The monthly expenditure rises steeply when the number of hired helps increase.

A majority of the patients took advice from the tertiary care hospitals for their acute care. Most of them also consulted private practitioners for their routine problems. Nineteen patients were consulting private practitioners exclusively. Most of the old people were consulting private practitioners, in most cases even before they became bedridden. Hence, private practitioners share a considerable burden of caring for the aged and disabled. This resource needs to be tapped to take the load off the tertiary care institutions. These practitioners can act as a bridge between the tertiary care institutions, which provide acute care, and the long-term care rendered by the families and other informal caregivers.

A high frequency of medical complications was observed in this study. Urinary infections were the most frequent medical complication. The rate of bedsores was much higher than those observed in the nationwide survey conducted by Institute of Medicine (IOM) in the US. ${ }^{15}$ Similarly, a high frequency of chest infections, bad smell and urinary incontinency shows that the technical quality of care provided to these patients was quite wanting. Bedsores, besides causing pain and infection, may also be a source of bad smell. In one case, presence of bedsores was the reason behind delay in surgery of spine.

Of the factors thought to affect quality of care received by subjects, only the fact that the subject had some property/assets to his name seemed to have a positive correlation. However, there are other factors, like the time since the subject has been bedridden, the expense of the care for the bedridden, the intensity of need for personal care which have not been evaluated in detail by the authors in this study but do deserve attention.

Poor correlation was observed between the feeling of satisfaction with the quality of care received, as perceived by subjects themselves and the quality of care as assessed by using objective criteria done by the authors. One interpretation may be that quality of care may hold different meanings from subjective and objective points of view. Subjects may perceive the complications of being bedridden, like bedsores, UTIs and constipation to be a natural by occurrence of being bedridden and not necessarily a complication in absence of awareness that these are preventable with good care. To a subject, the feeling of being loved, respected and being a part of the family may be more important than the occurrence of medical complications. This difference in perception of subjects and assessment by the authors needs further study. 


\section{Limitation}

Inspite of indirect verification of responses of the care givers, who responded on behalf of the patients who were unable to communicate, it is virtually impossible to get absolutely unbiased response from the caregivers due to a subjective feeling of their own efforts being evaluated. This needs to be kept in mind while drawing conclusions from responses of the caregivers.

\section{CONCLUSION}

Labor intensive LTC is provided by family members of the patients at great personal costs. Although, the personal needs of the elders are well taken care of, the high rate of complications reveals that technical quality of care is poor. Economic worth of the subjects positively affected the quality of care being received. Hence, schemes such as increase their earning capacity/insurance/savings rate or support by the government may be a tool to improve quality of care being provided at home and reduce episodes of hospitalization which consume precious resources of the family.

\section{REFERENCES}

1. Omran AR. The epidemiologic transition: a theory of the epidemiology of population change. The Milbank Quarterly 1971;49(4):509-538.

2. World Health Organization. Long-term care in developing countries. Geneva, World Health Organization 2002.
3. Strauss AL, Corbin J, Fagerhaug S, Glaser BG, Maines D, Suczek B, Wiener CL. Chronic Diseases and the Quality of Life. Mosby, St Louis. 2001.

4. World Health Organization. Health Situation in South East Asia Region 1998-2000. New Delhi, World Health Organization 2002.

5. Stessman J, Hammerman RR, Cohen A. A home hospitalization in the spectrum of community geriatric care. Disability and Rehabilitation 1997;19(4):134-141.

6. World Health Organization. Home based long-term care. Technical report series no. 898. Geneva. World Health Organisation 2000.

7. Adamchak DJ, Wilson AO, Nyanguru A, Hampson J. Elderly Support and Intergenerational Transfer in Zimbabwe: An Analysis by Gender, Marital Status and Place of Residence. Gerontologist 1991;31(4):505-513.

8. Al Shammari S, Jaraliah JS, Felibman F. Long-term care experience in Saudi Arabia. Social Sci Med 1997;44(5):693-697.

9. Donabedian A. The role of outcomes in quality assessment and assurance. Quality Review Bulletin 1992;18(11):356.

10. Census of India 2001. Registrar General and Census Commissioner of India. 2001.

11. Whiteneck GG, Charlifue SW, Grehart KA, Overhoiser JD. Quantifying handicap: a new measure of long-term rehabilitation outcomes. Archives of Physical Med Rehabilitat 1992;73(6):519-526.

12. Katz S, Ford AB, Moskowitz RW. Studies of Illness in the Aged. The index of activities of daily living: a standardize measure of biological and psychosocial function. J Am Med Assoc 1963;185(12):914-919.

13. Donabedian A. Quality of care: how it can be accessed. J Am Med Assoc 1998;260(12):1743-1748.

14. World Health Organization. Key policy issues in long-term care. Geneva, World Health Organisation 2003.

15. Improving the quality of care in nursing homes. Institute of medicine. National Academy of Sciences, USA 1987.

\section{Erratum}

The authors in Clinicopathological Conference Report-PM 25443 "Respiratory Distress in Acute Promyelocytic Leukemia after ATRA Therapy: Not always due to Differentiation Syndrome" [Apr-June 2015, Vol. 49(2):94-100] was an error and should be read as: Nandita Kakkar, Vani Bharani, Ojas Gupta, Deepa Shrestha, Ashim Das, Shano Naseem (Hematology Consultant), SC Varma. 